\title{
Orofacial Cleft 1
}

National Cancer Institute

\section{Source}

National Cancer Institute. Orofacial Cleft 1. NCI Thesaurus. Code C124838.

Cleft lip with or without cleft palate mapped to chromosome $6 \mathrm{p} 24$. 